\title{
Legume consumption and its association with fasting glucose, insulin resistance and type 2 diabetes in the Indian Migration Study
}

\author{
Preet K Dhillon 1,*, Liza Bowen², Sanjay Kinra ${ }^{2}$, Ankalmadugu Venkatsubbareddy \\ Bharathi $^{3}$, Sutapa Agrawal ${ }^{1}$, Dorairaj Prabhakaran ${ }^{1,4,5}$, Kolli Srinath Reddy ${ }^{5}$ and \\ Shah Ebrahim ${ }^{2}$ for the Indian Migration Study Group $†$ \\ ${ }^{1}$ Centre for Control of Chronic Conditions, Public Health Foundation of India, 4th floor, Plot 47, Sector 44, Gurgaon \\ 122002, Haryana, India: ${ }^{2}$ London School of Hygiene and Tropical Medicine, London, UK: ${ }^{3}$ Just Right Obesity \\ Clinic, Bangalore, India: ${ }^{4}$ Centre for Chronic Disease Control, Gurgaon, Haryana, India: ${ }^{5}$ Public Health Foundation \\ of India, Gurgaon, Haryana, India
}

Submitted 5 March 2015: Final revision received 15 February 2016: Accepted 26 April 2016: First published online 22 June 2016

\begin{abstract}
Objective: Legume consumption is associated with lower fasting glucose (FG) and insulin levels in nutrition trials and lower CVD mortality in large-scale epidemiological studies. In India, legumes are widely consumed in various preparations, yet no epidemiological study has evaluated the association of legumes with FG levels, insulin resistance and diabetes risk. The present study aimed to fill this gap.

Design: Fasting blood samples, in-person interviews to obtain information on demographic/socio-economic factors, physical activity, alcohol and tobacco use, and anthropometric measurements were collected. Dietary intakes were assessed by an interviewer-administered, validated, semi-quantitative FFQ.

Setting: Lucknow, Nagpur, Hyderabad and Bangalore, India.

Subjects: Men and women ( $n$ 6367) aged $15-76$ years - urban residents, urban migrants and their rural siblings.

Results: In multivariate random-effects models adjusted for age, BMI, total energy intake, macronutrients, physical activity and rural/migration status, daily legume consumption was not associated with FG $(P$-for-trend $=0.78)$, insulin resistance (homeostasis model assessment score; $P$-for-trend $=0.73$ ) or the prevalence of type 2 diabetes mellitus ( $P$-for-trend $=0 \cdot 41$ ). Stratified analyses by vegetarian diet and migration status did not change the findings. Inverse associations between legumes and FG emerged for participants with lower BMI and higher carbohydrate, protein, fat and sugar intakes.

Conclusions: Although legumes are essential in traditional Indian diets, as well as in prudent and Mediterranean diets in the West, we did not find an association between legumes and markers of glycaemic control, insulin resistance or diabetes, except for subgroups based on BMI and macronutrient intake. The ubiquitous presence and complexity of legume preparations in Indian diets may contribute to these findings.
\end{abstract}

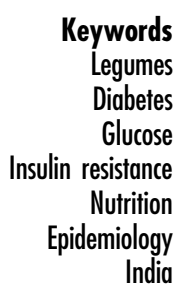

Diabetes affects $8.3 \%$ of (382 million) people worldwide $^{(1)}$, is the fourth most common cause of deaths from non-communicable disease globally ${ }^{(2)}$ and, similarly, is the fourth most common non-communicable disease in India, with an estimated 62.4 million people with diabetes and $77 \cdot 2$ million people with pre-diabetes ${ }^{(3)}$. Poor diet is an

$\dagger$ Membership of the Indian Migration Study Group is provided in the Acknowledgements. important risk factor (ranked highest in disability-adjusted life years ${ }^{(4)}$ ) for diabetes, as well as for non-communicable diseases, and includes high levels of salt, sugar, fat, processed and animal foods, and lower consumption of fruits and vegetables, whole grains and legumes ${ }^{(5,6)}$. Consumption of legumes - which comprise beans, lentils, peas, soyabeans and chickpeas ${ }^{(7)}$ - is recommended by the European $^{(8)}$, Canadian ${ }^{(9)}$ and American Diabetes Associations $^{(10)}$ as a means of increasing one's daily fibre 
intake and lowering glycaemic activity for diabetes control. In India, diabetes prevalence is increasing in both rural ${ }^{(11,12)}$ and urban ${ }^{(13-16)}$ populations, despite the consumption of traditional diets high in legumes including lentils, chickpeas, beans and peas ${ }^{(17)}$. Legumes have been shown to lower postprandial $^{(18)}$ as well as subsequent meal glycaemia ${ }^{(19)}$ and evidence from randomized nutrition trials shows that dietary pulses reduce fasting blood glucose and insulin levels in healthy persons, as well as those with high cholesterol, type 2 diabetes and coronary artery disease ${ }^{(17,20)}$. A meta-analysis of forty-one randomized trials on dietary pulses found significantly reduced levels of fasting blood glucose (standardized mean difference (SMD) $=-0 \cdot 82 ; 95 \%$ $\mathrm{CI}-1.36,-0.27)$ and insulin (SMD $=-0.49 ; 95 \% \mathrm{CI}-0.93$, -0.04) for pulses alone (eleven studies) as well as lower glycosylated protein levels in low-glycaemic-index and high-fibre diets ${ }^{(17)}$, although more recent studies are not as consistent ${ }^{(21)}$. Soluble fibres and the presence of $\alpha$-glucosidase inhibitors allow for slower absorption and reduction of the dietary glycaemic index. Epidemiological studies in the West have yielded inconsistent associations with legume intake $^{(22-29)}$ but the average daily intake in grams is much lower than in India, where evidence is also mixed with respect to associations with diabetes and glycaemic index ${ }^{(30,31)}$. Given the higher levels of legume consumption in traditional Indian diets, trends towards lower consumption patterns over time ${ }^{(32,33)}$ and concomitant quadrupling of diabetes prevalence since the 1970s (expected to touch 100 million people by $2030^{(5)}$ ), Indian populations can yield important information on the association between legumes and diabetes-related outcomes. Moreover, no large-scale data on these associations are available for diverse rural and urban populations across the country with detailed dietary data from validated FFQ. We evaluated the association between dietary legumes and fasting glucose, insulin resistance (as reflected by the homeostasis model assessment (HOMA) score) and diabetes in four geographic regions of rural and urban India.

\section{Methods}

\section{Ethics statement}

Questionnaires and information sheets were translated into local languages and informed consent was taken either by signature or a thumb print, if the participant was illiterate. Ethical approval was obtained from the All India Institute of Medical Sciences Ethics Committee (reference number A-60/4/8/2004) and the London School of Hygiene and Tropical Medicine, UK. The procedures followed were in accordance with the ethical standards of the Committee.

\section{Study population}

The Indian Migration Study (IMS) is a sib-pair comparison study to examine the effects of rural-to-urban migration on obesity and diabetes in four factories in north, south and central India - Lucknow (Hindustan Aeronautical Ltd), Nagpur (Indorama Synthetics, Ltd), Hyderabad (Bharat Heavy Electricals Ltd) and Bangalore (Hindustan Machine Tools Ltd) - from 1 March 2005 to 31 December 2007. The study details and major findings have been described in detail elsewhere ${ }^{(34)}$. Briefly, factory workers and their cohabitant spouses were eligible if employer records indicated they were rural-to-urban migrants. Factory workers and spouses were asked to identify same-sex siblings of the closest age who still resided in their rural place of origin. Same-sex siblings were given preference over those of similar age; for multiple same-sex siblings, the closest one in age was recruited into the study. For non-migrants, a $25 \%$ random sample of urban factory workers was also chosen, as well as their urbandwelling siblings who did not work in the same factory.

\section{Dietary intake}

Diet was assessed using a semi-quantitative FFQ that captured common dietary patterns across all four sites, which has been described in detail elsewhere ${ }^{(35)}$. Participants were asked to report their frequency of intake (daily, weekly, monthly, yearly/never) of 184 items over a one-year period based on standardized serving sizes (e.g. tablespoon, ladle, bowl). Nutrient databases were developed using the Indian food composition tables ${ }^{(36)}$ and the US Department of Agriculture's nutrient database (release no. 14) $)^{(37)}$ or McCance and Widdowson's The Composition of Foods ${ }^{(38)}$ where nutrient values were unavailable from the Indian food composition tables. Specific databases for cooking oil were created to account for fat composition variations of cooking oils commonly consumed in India. Nutrient composition was determined from weighed recipes (using digital scales accurate to $1 \mathrm{~g}$ ) collected from participants who regularly prepared these foods, under the supervision of a nutritionist, in rural and urban areas in each of the four regions ${ }^{(35)}$. Recipes were checked for face validity with nutritionists and other study participants.

Legumes included pulses and whole gram preparations (e.g. sambhar, dal, curries, vada) as well as dishes in which pulses were added to other ingredients (e.g. idli, dosa mixture, bajii and specific regional recipes). The weight of legumes in each preparation was added across the 184 items to derive a daily consumption of legumes, in grams. Other food groups considered in the current analysis included vegetables (including those added to preparations), cereals, sugar (sugar and jaggery used in preparations), salt, meat (including meat added to mixed dishes), fish and dairy products. Three $24 \mathrm{~h}$ recalls were conducted in a sub-sample of participants ( $n$ 530, 53.9\% male) to validate the FFQ. A sub-sample was re-interviewed after the completion of the FFQ (1-2 months, $n 185$ and 12 months later, $n$ 305), yielding $\kappa$ coefficients of $0 \cdot 26-$ $0 \cdot 71^{(35)}$, which are similar to reliability estimates from other studies ${ }^{(39,40)}$. The validities for macronutrients ranged from 0.29 (fats) to 0.51 (carbohydrates); the $\kappa$ and Spearman 
correlation coefficients for validity of legumes were 0.39 and 0.54 , respectively ${ }^{(35)}$.

\section{Socio-economic status, physical activity}

Interviewer-administered questionnaires captured additional information on sociodemographic and lifestyle factors such as physical activity, tobacco and alcohol use. A sub-set of questions (14/29) from the Standard of Living Index (SLI) was selected according to a priori knowledge and what would be most informative for this population ${ }^{(34)}$, with the same weights applied to each item as those used by the Indian Institute for Population Sciences to derive an SLI score $(\text { maximum }=38)^{(41)}$. This household-level asset-based score has been devised for large-scale Indian surveys ${ }^{(41)}$ and is a strong indicator of an individual's socio-economic status and the changes that occur with migration ${ }^{(34,42,43)}$. A semi-quantitative physical activity questionnaire (IMSPAQ) was used to assess daily activity for work, household chores, leisure time, sedentary activities, sleep and other common activities. Participants reported the frequency (daily, 1 time/week, 2-4 times/week, 5-6 times/week, 1 time/month and 2-3 times/month) and duration of each activity over the past month. Physical activity was calculated in metabolic equivalents of task (MET), with details described elsewhere ${ }^{(44,45)}$. Validation in a sub-sample of rural ( $n$ 49) and urban ( $n$ 45) participants yielded modest correlations with accelerometry $(r=0.28, P<0.01)$ and a $24 \mathrm{~h}$ activity diary $(r=0 \cdot 30, P<0 \cdot 01)^{(44)}$.

\section{Outcomes}

Anthropometric measurements have been described in detail elsewhere ${ }^{(34)}$; weight obtained using a digital scale (model PS16) and standing height using a Leicester height measure (Chasmors, Ltd) were used to determine BMI $\left(\mathrm{kg} / \mathrm{m}^{2}\right)$. A diagnosis of diabetes was made according to the WHO criterion of fasting plasma glucose $>7.0 \mathrm{mmol} / \mathrm{l}^{(46)}$ or a report of doctor-diagnosed disease. Fasting blood samples were collected and the time of the last meal was recorded. Glucose was measured on the same day as blood collection in local laboratories with the GOD-PAP method using RANDOX kits ${ }^{(47)}$. Insulin was measured using kits from MERCODIA (Uppasala, Sweden) using the solid-phase twosite enzyme immunoassay method based on the direct sandwich technique. The kit had traceability to the 1 st International Reference Preparation 66/304 and the laboratory participated in the UK NEQAS (UK National External Quality Assessment Service) scheme for insulin. The remainder of the blood samples were stored locally at $-20^{\circ} \mathrm{C}$ and transported to the All India Institute of Medical Sciences, New Delhi on a monthly basis for storage at $-70^{\circ} \mathrm{C}$. Local assay quality was checked using regular external standards and internal duplicate assays, and monitored by the Cardiac Biochemistry Laboratory of the All India Institute of Medical Sciences, which is part of the UK NEQAS (http://www.ukneqas.org.uk/) scheme for quality assurance.
Insulin resistance was reflected by the HOMA score, which was calculated from fasting blood glucose and serum insulin levels using the equation: [plasma glucose $(\mathrm{mol} / \mathrm{l}) \times$ plasma insulin $(\mathrm{mU} / \mathrm{l})] / 22 \cdot 5$, based on the original formula ${ }^{(48)}$, which has been validated through biochemical indicators in healthy Indians with moderate correlations $^{(49)}$.

\section{Statistical analysis}

We conducted multilevel models ${ }^{(50)}$ to account for the correlated data structure arising from selection of urban- and rural-dwelling sibling pairs, described in detail previously ${ }^{(34)}$. Briefly, data cannot be treated as independent; the between-pair variation is explicitly modelled, a random shift in intercept is applied to both siblings in a pair, and pair-specific random effects allow for a comparison of between-pair $v$. within-pair variation. The urban-rural sibling pair and factory site variables were explicitly included in the model to adjust for within-pair and within-factory correlations. Logistic random-effects models were used for analyses on diabetes, while linear random-effects models were used for fasting glucose and HOMA score, and the Wald test was used for determining levels of significance $(P<0.05)$. The daily amount of legumes was calculated in quartiles for the main analyses and as a continuous, logtransformed variable for subgroup analyses, to normalize skewed distributions and to enhance statistical power in site- and group-stratified analyses with smaller numbers. The proportion of energy from legumes was determined by dividing the daily intake of legumes (grams converted into kcal) by the total energy intake (kcal). For each food item containing legumes, the percentage legume contribution was based on grams of legumes in each dish divided by the total cooked weight per dish (in grams). Multivariate analyses adjusted for important confounders and predictors of these outcomes, including age (continuous, years), socio-economic status (SLI score, range 1-36), occupation (manual labour, yes/no), urban $v$. rural residence, physical activity (daily MET), BMI $\left(\mathrm{kg} / \mathrm{m}^{2}\right.$ ), total energy intake (daily, $\mathrm{kcal}$ ), vegetables (daily intake, grams), cereals (daily intake, grams), sugar (daily intake, grams), and fats and oils (daily intake, grams). Continuous dietary variables were logtransformed to adjust for the skewed nature of the intake distribution. Stratified analyses were conducted to evaluate the effects of legume consumption on fasting glucose, HOMA score and diabetes outcomes according to BMI, gender, site, migration status, macronutrient intakes (carbohydrate, fat and protein) and vegetarian diet. Continuous and categorical variables were compared using ANOVA and the $F$ test for evaluating the difference in means across quartiles of legume consumption. Spearman correlation coefficients were calculated for legumes and individual food items as well as macronutrient intakes. All analyses were conducted using the statistical software package STATA 10. 
Table 1 Demographic, lifestyle and biological characteristics of the population, Indian Migration Study

\begin{tabular}{|c|c|c|c|c|}
\hline & \multirow{2}{*}{$\frac{\text { Men }(n 3717)}{\text { Mean, sD or } \%}$} & \multirow{2}{*}{$\frac{\text { Women }(n \text { 2650) }}{\text { Mean, sD or \% }}$} & \multicolumn{2}{|c|}{ Total ( $N$ 6367) } \\
\hline & & & $n$ & Mean, SD or $\%$ \\
\hline Age (years), mean & $40 \cdot 7$ & $39 \cdot 2$ & 6367 & $40 \cdot 1$ \\
\hline SD & $10 \cdot 6$ & $9 \cdot 8$ & & $10 \cdot 3$ \\
\hline Married (\%) & $85 \cdot 9$ & $88 \cdot 7$ & 5542 & $87 \cdot 0$ \\
\hline Manual labour (\%) & $60 \cdot 9$ & $10 \cdot 9$ & 2550 & $40 \cdot 0$ \\
\hline Secondary education (\%) & $64 \cdot 2$ & $75 \cdot 9$ & 4834 & $75 \cdot 9$ \\
\hline Hindu religion (\%) & $92 \cdot 3$ & $90 \cdot 3$ & 2550 & $91 \cdot 2$ \\
\hline \multicolumn{5}{|l|}{ Caste (\%) } \\
\hline Scheduled caste/tribe & $22 \cdot 0$ & $20 \cdot 6$ & 1312 & $20 \cdot 6$ \\
\hline Other backward classes & $34 \cdot 0$ & $36 \cdot 0$ & 2289 & $36 \cdot 0$ \\
\hline Non-backward class & $44 \cdot 0$ & 43.4 & 2764 & 43.4 \\
\hline \multicolumn{5}{|l|}{ Migrant status (\%)† } \\
\hline Rural & 26.5 & 33.0 & 1860 & $29 \cdot 2$ \\
\hline Rural-to-urban migrant & $44 \cdot 7$ & $29 \cdot 0$ & 2432 & $38 \cdot 2$ \\
\hline Urban & $28 \cdot 7$ & 37.4 & 2059 & $32 \cdot 3$ \\
\hline BMI $\left(\mathrm{kg} / \mathrm{m}^{2}\right)$, mean & $23 \cdot 0$ & $24 \cdot 4$ & 6367 & $23 \cdot 6$ \\
\hline SD & 3.9 & $5 \cdot 0$ & & 4.5 \\
\hline Daily physical activity $(\mathrm{MET} \times \mathrm{h} / \mathrm{d})$, mean & $39 \cdot 7$ & $37 \cdot 9$ & 6367 & $39 \cdot 0$ \\
\hline SD & 4.9 & $4 \cdot 1$ & & 4.7 \\
\hline \multicolumn{5}{|l|}{ Biological measurements } \\
\hline Glucose $(\mathrm{mmol} / \mathrm{l})$, mean & $5 \cdot 2$ & $5 \cdot 1$ & 6367 & $5 \cdot 0$ \\
\hline SD & 1.0 & 1.0 & & 1.0 \\
\hline Insulin (mU/l), mean & 7.5 & 8.0 & 6367 & $7 \cdot 7$ \\
\hline SD & $8 \cdot 9$ & $19 \cdot 1$ & & $14 \cdot 1$ \\
\hline
\end{tabular}

MET, metabolic equivalent of task.

†Includes reverse urban-to-rural migrants (n 16).

\section{Results}

Participants comprised rural (29\%), migrant (38\%) and urban (32\%) residents, and represented four geographic regions of India - Lucknow, Uttar Pradesh (28\%), Nagpur, Maharashtra (25\%), Hyderabad, Andhra Pradesh (27\%) and Bangalore, Karnataka (20\%). The average BMI was high for Indian men $\left(23.0 \mathrm{~kg} / \mathrm{m}^{2}\right)$ and women $\left(24.4 \mathrm{~kg} / \mathrm{m}^{2}\right)$ compared with national averages of $20.3 \mathrm{~kg} / \mathrm{m}^{2}$ for men $15-54$ years and $20.5 \mathrm{~kg} / \mathrm{m}^{2}$ for women $15-49$ years ${ }^{(41)}$, even though $40 \%$ of study participants were involved in manual labour (Table 1). A total of 193 participants were previously diagnosed with type 2 diabetes (3.0\%).

The median daily consumption of legumes in this population was $52.1 \mathrm{~g}$, with $24 \%$ higher consumption in men $(57.3 \mathrm{~g})$ than women $(46 \cdot 1 \mathrm{~g})$. Legume consumption was higher for younger persons, those with a higher standard of living, a secondary education and more physical activity (Table 2). Legume intake was moderately positively correlated with total energy intake, macronutrient intakes and with important components of the diet, such as fats and oils (correlation coefficients $=0 \cdot 41-$ $0 \cdot 74$ ), particularly in female migrants (see online supplementary material, Supplemental Fig. 1).

We evaluated each site according to macronutrient components of the regional diet and found that Nagpur participants primarily used soyabean oil for cooking (66.5\%) that corresponded to the highest intake of polyunsaturated fat $(34.4 \mathrm{~g})$ compared with the other sites, which used either mustard oil (Lucknow, 81.8\%) or sunflower oil (Hyderabad and Bangalore, 63.5\% and $72.0 \%$, respectively; Table 3 ). The site with the lowest legume consumption (Hyderabad, $35.5 \mathrm{~g} / \mathrm{d}$ ) also had the highest consumption of meat products (86\%) and the lowest amount of fibre $(11.5 \mathrm{~g} / \mathrm{d}$; Table 3$)$. We evaluated site-specific associations between daily legume consumption (in grams) and fasting glucose, because the constitution and preparation of a dish can vary considerably by geographic site with respect to the quantity of legumes and other ingredients added, method of cooking and type of cooking oil. We found an inverse association between fasting glucose and legume consumption (quartiles) for the site of Nagpur ( $P$-for-trend=0.026), a marginally significant association in Lucknow ( $P$-fortrend $=0.05)$ and no evidence of association $(P>0.05)$ in the other two sites, Hyderabad and Bangalore (Table 3 ).

When we evaluated all sites together, we found no association between quartiles of legume consumption and fasting glucose $(\beta(\mathrm{mmol} / \mathrm{l}): \beta(\mathrm{Q} 2)=0.62 ; 95 \% \mathrm{CI}$ $-0.70, \quad 1.94 ; \quad \beta \quad(\mathrm{Q} 3)=0.49 ; \quad 95 \% \quad$ CI $-0.99, \quad 1.98$; $\beta(\mathrm{Q} 4)=-0 \cdot 10 ; 95 \% \mathrm{CI}-1 \cdot 81,1 \cdot 61$; Table 4$)$. There was also no association between legume consumption and insulin resistance, in terms of HOMA score $(\beta(\mathrm{Q} 2)=-0 \cdot 10 ; 95 \% \mathrm{CI}-0 \cdot 24,0 \cdot 03 ; \beta(\mathrm{Q} 3)=-0 \cdot 05 ; 95 \%$ CI $-0 \cdot 21,0 \cdot 10 ; \beta(\mathrm{Q} 4)=-0 \cdot 06 ; 95 \% \mathrm{CI} ;-0 \cdot 24,0 \cdot 11)$. Null associations were also observed for type 2 diabetes and legumes (relative risk $(\mathrm{RR})(\mathrm{Q} 2)=1 \cdot 69 ; 95 \% \mathrm{CI} 0 \cdot 86,3 \cdot 30$, $\mathrm{RR}(\mathrm{Q} 3)=1 \cdot 52 ; 95 \%$ CI $0 \cdot 75,3 \cdot 09 ; \mathrm{RR}(\mathrm{Q} 4)=1 \cdot 68 ; 95 \% \mathrm{CI}$ $0 \cdot 76,3 \cdot 72$; Table 4 ). In evaluating whether the association between legume consumption and fasting glucose varied 
Table 2 Distribution of population characteristics by quartile of legume consumption, Indian Migration Study

\begin{tabular}{|c|c|c|c|c|c|c|c|c|c|}
\hline & \multicolumn{8}{|c|}{ Quartile of daily legume intake $†$} & \multirow[b]{3}{*}{$P$ value } \\
\hline & \multicolumn{2}{|c|}{ Q1 (n 1558) } & \multicolumn{2}{|c|}{ Q2 (n 1598) } & \multicolumn{2}{|c|}{ Q3 (n 1591) } & \multicolumn{2}{|c|}{ Q4 (n 1620) } & \\
\hline & Mean or \% & SD & Mean or \% & SD & Mean or \% & SD & Mean or \% & SD & \\
\hline Age (years) & 41.6 & $10 \cdot 5$ & $40 \cdot 1$ & $10 \cdot 3$ & 39.7 & $10 \cdot 0$ & $39 \cdot 0$ & $10 \cdot 2$ & $<0.0001 \S$ \\
\hline Gender (\% male $)$ & 49.9 & - & 53.4 & - & $59 \cdot 0$ & - & $70 \cdot 9$ & - & $<0.0001 \|$ \\
\hline Place of residence (\% rural) & 43.5 & - & $32 \cdot 4$ & - & 31.5 & - & 43.9 & - & $0.25 \|$ \\
\hline SLI‡ & 17.9 & $7 \cdot 2$ & $20 \cdot 1$ & $6 \cdot 1$ & $21 \cdot 0$ & $6 \cdot 1$ & $21 \cdot 0$ & $6 \cdot 1$ & $<0.0001 \S$ \\
\hline Manual labourer (\%) & $42 \cdot 0$ & - & $35 \cdot 9$ & - & $36 \cdot 1$ & - & $46 \cdot 2$ & - & $0.01 \|$ \\
\hline Secondary education (\%) & 58.7 & - & $77 \cdot 2$ & - & $82 \cdot 8$ & - & 84.4 & - & $<0.0001 \|$ \\
\hline $\mathrm{BMI}\left(\mathrm{kg} / \mathrm{m}^{2}\right)$ & 23.7 & $4 \cdot 8$ & 23.7 & 4.4 & 23.9 & $4 \cdot 3$ & $23 \cdot 2$ & $4 \cdot 3$ & $<0.0001 \S$ \\
\hline Physical activity $(\mathrm{MET} \times \mathrm{h} / \mathrm{d})$ & 38.5 & 4.9 & 38.6 & 4.5 & 39.0 & 4.5 & $39 \cdot 7$ & $4 \cdot 7$ & $<0.0001 \S$ \\
\hline Fasting glucose $(\mathrm{mmol} / \mathrm{l})$ & 5.03 & 0.7 & $5 \cdot 13$ & 1.1 & $5 \cdot 21$ & $1 \cdot 1$ & $5 \cdot 15$ & $1 \cdot 1$ & $0.0002 \S$ \\
\hline \multicolumn{10}{|l|}{ Lipid profile } \\
\hline Cholesterol $(\mathrm{mmol} / \mathrm{l})$ & $4 \cdot 71$ & 1.1 & 4.69 & 1.2 & 4.70 & 1.2 & 4.66 & $1 \cdot 1$ & $0.48 \S$ \\
\hline TAG $(\mathrm{mmol} / \mathrm{l})$ & 1.44 & 0.7 & 1.43 & 0.8 & 1.45 & 0.7 & 1.46 & 0.8 & $0.74 \S$ \\
\hline HDL cholesterol (mmol/l) & $1 \cdot 16$ & 0.2 & $1 \cdot 15$ & 0.3 & $1 \cdot 18$ & 0.2 & $1 \cdot 16$ & 0.3 & $0.08 \S$ \\
\hline
\end{tabular}

SLI, Standard of Living Index; MET, metabolic equivalent of task.

†Legume consumption quartiles (Q): Q1, 0-32.95, median 23.5 g/d; Q2, 32.96-51.83, median 42.4 g/d; Q3, 51.84-77.31, median 63.8 g/d; Q4, 77.32-547.7, median $100.7 \mathrm{~g} / \mathrm{d}$. Median consumption was significantly different across quartiles $(P=0.001)$.

$\neq S L I$ range is $1-36$ (median $=21$, interquartile range $=15-25$ ).

$\S F$ test for ANOVA testing difference in means across quartiles of legume consumption.

IISpearman rank-correlation test for the difference in proportions across quartiles of legume consumption.

Table 3 Dietary patterns and associations $\nmid$ between daily legume consumption and fasting glucose levels, according to study site, Indian Migration Study

\begin{tabular}{|c|c|c|c|c|c|c|c|c|}
\hline \multirow[b]{2}{*}{ Daily intake } & \multicolumn{2}{|c|}{ Lucknow (n 1806) } & \multicolumn{2}{|c|}{ Nagpur (n 1586) } & \multicolumn{2}{|c|}{ Hyderabad ( $n$ 1727) } & \multicolumn{2}{|c|}{ Bangalore ( $n$ 1248) } \\
\hline & Mean & SD & Mean & SD & Mean & SD & Mean & SD \\
\hline Protein $(\mathrm{g})$ & 87.5 & 29.2 & $92 \cdot 3$ & $28 \cdot 1$ & 68.1 & $26 \cdot 9$ & $82 \cdot 2$ & 29.9 \\
\hline Fat $(\mathrm{g})$ & $80 \cdot 1$ & $30 \cdot 6$ & 98.2 & $39 \cdot 0$ & $73 \cdot 1$ & 34.5 & $86 \cdot 8$ & 37.9 \\
\hline Fibre $(\mathrm{g})$ & 14.7 & 5.5 & $16 \cdot 5$ & $5 \cdot 7$ & $11 \cdot 1$ & 5.5 & $15 \cdot 7$ & $7 \cdot 3$ \\
\hline Carbohydrates (g) & 435.4 & $141 \cdot 3$ & $529 \cdot 2$ & $152 \cdot 7$ & $404 \cdot 3$ & 140.5 & 480.9 & $159 \cdot 8$ \\
\hline Total grams & 1934.5 & $627 \cdot 3$ & 2121.6 & 634.4 & $2175 \cdot 0$ & 746.4 & $2645 \cdot 9$ & 871.6 \\
\hline Non-vegetarian diet (\%) & \multicolumn{2}{|r|}{$44^{0<1 \cdot 0}$} & \multicolumn{2}{|r|}{$62^{034 \cdot 4}$} & \multicolumn{2}{|r|}{$86^{140.4}$} & \multicolumn{2}{|r|}{68} \\
\hline Legumes $(\mathrm{g})$ & $75 \cdot 2$ & 37.5 & 64.9 & 35.8 & 35.5 & $25 \cdot 7$ & $66 \cdot 6$ & 35.8 \\
\hline Main oil (type \& \%) & \multicolumn{2}{|c|}{$\begin{array}{c}\text { Mustard } \\
81.8\end{array}$} & \multicolumn{2}{|c|}{$\begin{array}{c}\text { Soyabean } \\
66.5\end{array}$} & \multicolumn{2}{|c|}{$\begin{array}{c}\text { Sunflower } \\
63.5\end{array}$} & \multicolumn{2}{|c|}{$\begin{array}{c}\text { Sunflower } \\
72.0\end{array}$} \\
\hline MUFA (g) & $30 \cdot 7$ & 13.0 & $30 \cdot 5$ & $17 \cdot 8$ & 20.5 & 10.7 & 23.1 & 11.8 \\
\hline PUFA (g) & $16 \cdot 7$ & $10 \cdot 1$ & 34.4 & $15 \cdot 7$ & $25 \cdot 8$ & $15 \cdot 4$ & $27 \cdot 0$ & 14.3 \\
\hline SFA $(g)$ & $25 \cdot 6$ & $11 \cdot 0$ & $25 \cdot 0$ & $11 \cdot 9$ & $21 \cdot 2$ & $11 \cdot 0$ & $30 \cdot 3$ & 14.5 \\
\hline Legume consumption $(\mathrm{g} / \mathrm{d})$ & $\beta$ & $95 \% \mathrm{Cl}$ & $\beta$ & $95 \% \mathrm{Cl}$ & $\beta$ & $95 \% \mathrm{Cl}$ & $\beta$ & $95 \% \mathrm{Cl}$ \\
\hline $\begin{array}{l}\text { Q1 } \\
\text { Q2 } \\
\text { Q3 } \\
\text { Q4 } \\
P \text { test-for-trend } \neq\end{array}$ & $\begin{array}{l}1.00 \\
3.75 \\
3.86 \\
5.07\end{array}$ & $\begin{array}{c}\text { Ref. } \\
-0.33,7.83 \\
-0.11,7.82 \\
0.79,9.34 \\
0.05\end{array}$ & $\begin{array}{r}1.00 \\
-1.49 \\
-2.80 \\
-3.84\end{array}$ & $\begin{array}{c}\text { Ref. } \\
-3.40,0.41 \\
-4.83,-0.78 \\
-6.08,-1.59 \\
<0.001\end{array}$ & $\begin{array}{r}1.00 \\
0.25 \\
-0.34 \\
0.87\end{array}$ & $\begin{array}{l}\text { Ref. } \\
-0.97,1.47 \\
-2.11,1.43 \\
-1.94,3.68 \\
0.86\end{array}$ & $\begin{array}{r}1.00 \\
-0.53 \\
-0.77 \\
-4.25\end{array}$ & $\begin{array}{c}\text { Ref. } \\
-5.08,4.02 \\
-5.93,4.38 \\
-10.58,2.08 \\
0.18\end{array}$ \\
\hline
\end{tabular}

Ref., reference category.

†Random effects linear (legumes and fasting glucose) regression models adjusting for age, within-pair correlation, Standard of Living index, BMl ( $\mathrm{kg} / \mathrm{m}^{2}$ ), daily fat intake (grams), daily vegetable intake (grams), daily cereal intake (grams), daily energy intake (kcal), total physical activity (MET×h/d, where $\mathrm{MET}=$ metabolic equivalent of task), living in rural area (yes/no) and manual labour (yes/no).

$\ddagger P$ value of test for linear trend.

by macronutrient intake, we found significant inverse associations for those in the highest tertiles of carbohydrate, protein, fat and sugar intakes, and for those in the lowest tertile of BMI (Fig. 1). The association of legumes and fasting glucose did not change after evaluating subgroups according to gender, vegetarian diet (yes/no) and migration status (rural, urban, migrant; Fig. 1).

\section{Discussion}

Overall, we found no association between legume consumption and fasting glucose, HOMA score or diabetes in populations representing four geographic regions and diets of India. An inverse association emerged between legume intake and fasting glucose for those with the highest daily intakes of carbohydrate, protein, fat and sugar, for the 
Table 4 Multivariate associations $\nmid$ between legume consumption $\ddagger$ and fasting glucose, insulin resistance (homeostasis model assessment) and type 2 diabetes, Indian Migration Study

\begin{tabular}{|c|c|c|c|c|c|c|c|c|c|}
\hline & \multicolumn{3}{|c|}{ Fasting glucose } & \multicolumn{3}{|c|}{ Insulin resistance (HOMA score) } & \multicolumn{3}{|c|}{ Type 2 diabetes } \\
\hline & $\beta$ & $95 \% \mathrm{Cl}$ & $P$ value & $\beta$ & $95 \% \mathrm{Cl}$ & $P$ value & $\beta$ & $95 \% \mathrm{Cl}$ & $P$ value \\
\hline \multicolumn{10}{|l|}{ Unadjusted } \\
\hline Q1 & 1.00 & Ref. & - & 1.00 & Ref. & - & 1.00 & Ref. & - \\
\hline Q2 & 0.63 & $-0.63,1.89$ & 0.33 & -0.10 & $-0.23,0.04$ & 0.15 & 1.66 & $0.91,3.02$ & 0.10 \\
\hline Q3 & 0.64 & $-0.69,1.98$ & 0.34 & -0.03 & $-0.18,0.11$ & 0.63 & 1.60 & $0.87,2.92$ & 0.13 \\
\hline Q4 & -0.36 & $-1.75,1.04$ & 0.62 & -0.14 & $-0.29,0.001$ & 0.05 & 1.53 & $0.83,2.81$ & 0.18 \\
\hline \multicolumn{10}{|c|}{ Age-adjusted only } \\
\hline Q1 & 1.00 & Ref. & - & 1.00 & Ref. & - & 1.00 & Ref. & - \\
\hline Q2 & 0.66 & $-0.59,1.91$ & 0.3 & -0.10 & $-0.23,0.04$ & 0.15 & 1.70 & $0.93,3.13$ & 0.09 \\
\hline Q3 & 0.74 & $-0.58,2.07$ & 0.27 & -0.03 & $-0.17,0.11$ & 0.64 & 1.66 & $0.90,3.06$ & 0.11 \\
\hline Q & $-0 \cdot 12$ & $-1.51,1.26$ & 0.86 & -0.14 & $-0.29,0.00$ & 0.05 & 1.60 & $0.86,2.98$ & 0.14 \\
\hline \multicolumn{10}{|c|}{ Multivariate analysis } \\
\hline Q1 & 1.00 & Ref. & - & 1.00 & Ref. & - & 1.00 & Ref. & - \\
\hline Q2 & 0.62 & $-0.70,1.94$ & 0.36 & -0.10 & $-0.24,0.03$ & 0.14 & 1.69 & $0.86,3.30$ & 0.13 \\
\hline Q3 & 0.49 & $-0.99,1.98$ & 0.51 & -0.05 & $-0.21,0.10$ & 0.5 & 1.52 & $0.75,3.09$ & 0.25 \\
\hline Q4 & -0.10 & $-1.81,1.61$ & 0.91 & -0.06 & $-0.24,0.11$ & 0.48 & 1.68 & $0.76,3 \cdot 72$ & 0.20 \\
\hline$P$-for-trend§ & & & 0.78 & & & 0.73 & & & 0.41 \\
\hline
\end{tabular}

HOMA, homeostasis model assessment; $R R$, risk ratio; Ref., reference category.

†Random-effects linear (fasting glucose and insulin resistance) and logistic (type 2 diabetes) regression models adjusting for within-pair correlation, site and age, Standard of Living Index, BMI, vegetables (grams), cereals (grams) and total intake (kcal), total physical activity (MET $\times \mathrm{h} / \mathrm{d}$, where MET = metabolic equivalent of task), living in rural area (yes/no) and manual labour (yes/no).

łLegume consumption quartiles (Q): Q1, 0-32.95 g/d; Q2, 32.96-51.83 g/d; Q3, 51.84-77.31 g/d; Q4, 77.32-547.7 g/d.

$\S P$ value of test for linear trend.

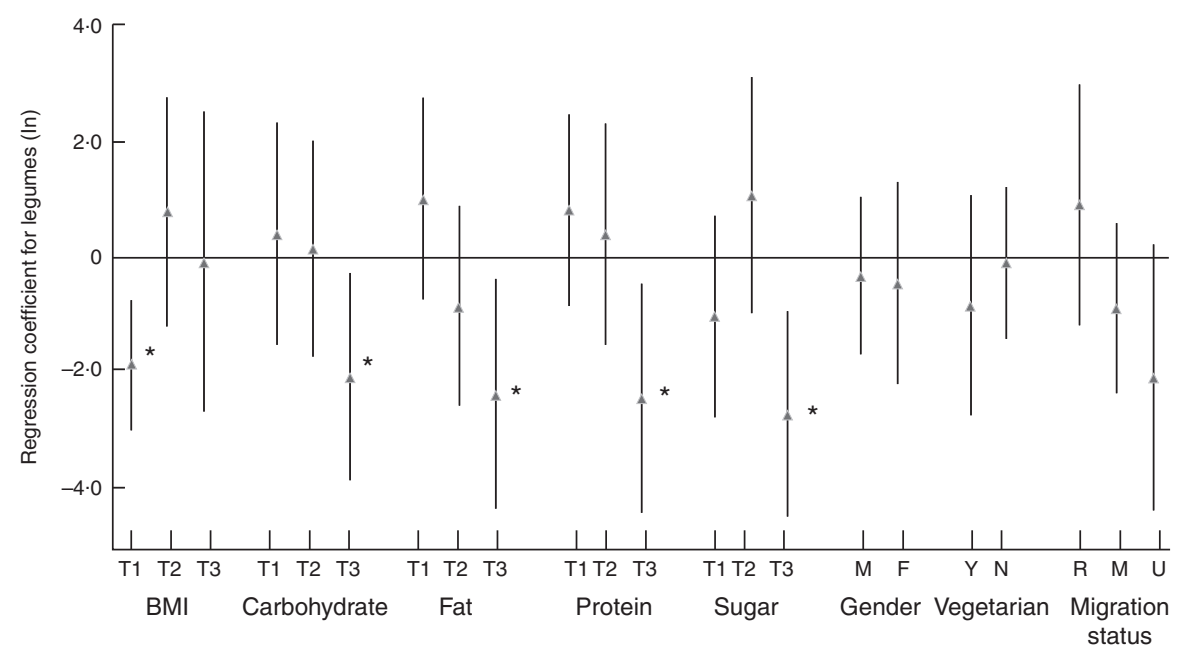

Fig. 1 Association† between legumes and fasting glucose according to $B M I$, macronutrients (T, tertile), gender ( $M$, male; $F$, female), vegetarian status ( $\mathrm{Y}$, yes; $\mathrm{N}, \mathrm{no}$ ) and migration status ( $\mathrm{R}$, rural, $\mathrm{M}$, migration; $\mathrm{U}$, urban), Indian Migration Study. ${ }^{*} P<0.05$. $†$ Multivariate linear regression coefficients, and their $95 \% \mathrm{Cl}$ represented by vertical bars, adjusted for age, Standard of Living $\mathrm{Index}, \mathrm{BMI}\left(\mathrm{kg} / \mathrm{m}^{2}\right)$, daily energy intake (kcal), daily fat intake (grams), daily vegetable intake (grams), daily sugar intake (grams), daily cereal intake (grams), total physical activity (MET $\times \mathrm{h} / \mathrm{d}$, where $\mathrm{MET}=$ metabolic equivalent of task) and living in rural area (yes/no)

lowest BMI tertile, and for the site of Nagpur (which has the highest carbohydrate, protein, fat and fibre intakes of the four sites). The association did not vary by gender, vegetarian diet, migration status or history of self-reported diabetes, although the range of intake varied more than fourfold across the study population, with differences by geographic region. The conclusions remained the same if potential intermediates in the pathway, such as BMI, physical activity and total energy, were removed from regression models.
It has been suggested that diets high in legumes are beneficial for the prevention and management of type 2 diabetes, as well as for lowering serum glucose and cholesterol $^{(51)}$, because they are wholegrain foods with high insoluble fibre and low glycaemic index ${ }^{(33,52)}$. Evaluations of dietary patterns have identified legumes as an important component of the 'prudent' diet ${ }^{(53)}$, the Alternative Healthy Eating Index (AHEI) ${ }^{(54)}$ and the Mediterranean diet ${ }^{(55)}$, which have been associated with a lower risk of diabetes in some $e^{(54,56,57)}$ but not all ${ }^{(53)}$ large cohort studies. 
The epidemiological data focusing on legumes specifically showed inverse associations between legumes and diabetes in some ${ }^{(22-26,30)}$ but not all ${ }^{(25,27-29,31)}$ studies, including one population-based study in India reporting an inverse association between legume intake and selfreported diabetes ${ }^{(30)}$. The authors were restricted to National Family Health Survey-3 questions on frequency intake without quantitative measures, were unable to control for total energy intake (which is correlated with legume intake) or other confounders, such as physical activity and assessed self-reported diabetes, which may be subject to temporal ambiguity of diabetic patients increasing legume intake as a result of their diagnosis. In studies conducted in Asian countries, the inverse associations are primarily due to soya intake ${ }^{(24,26,58)}$. One reason for the lack of an association in our study may be that soya is not commonly consumed in Indian diets. Soyabean oil was, however, the primary cooking oil at one site, Nagpur, for which an inverse association emerged for legumes and fasting glucose. Soyabean oil consists primarily of PUFA and studies have shown that PUFA intake is associated with a reduced risk of diabetes and glycaemic control $^{(59-65)}$.

Legume consumption is nearly ubiquitous in Indian diets - $99 \%$ of participants reported consuming legume dishes - and the lack of a comparison group with no legume intake may be another reason for the lack of an association in our study. The average daily intake of the reference group (Q1) in our study population was $23.5 \mathrm{~g} / \mathrm{d}$, which corresponds to high levels in other populations ${ }^{(22,24)}$; only two participants consumed $3 \mathrm{~g} / \mathrm{d}$, which was classified as 'high' consumption associated with lower glucose intolerance rates in one previous study ${ }^{(22)}$. Only one published study on legumes showed intake greater than the current study population in the reference group ( $29 \mathrm{~g} / \mathrm{d}$ in the lowest quintile), in which the authors also reported no association between legumes (soya) intake and type 2 diabetes in Japanese women ${ }^{(25)}$. This may partly explain why we observed inverse associations in only the highest tertiles of carbohydrate, protein, fat and sugar consumption, where these participants' legume consumption was significantly higher $(P<0.0001$; data not shown) than in the lowest tertiles; we also found higher mean legume intake in persons of lower BMI compared with those of higher BMI $(P=0 \cdot 02$; data not shown). The relatively high levels of intake in our study population is due to the wide range of preparations for legume dishes in these four regions, including dals, vegetables, cereals, sweets, salads, chutneys and fried snacks. When we evaluated the association between legumes and fasting glucose according to the type of legume dish, the conclusions remained the same $(P>0.05$; data not shown). Of 184 food items on the FFQ, fifty-five contained legumes, ranging from 2 to $77 \%$ weight contribution, varying according to the preparation method and geographic location. We also evaluated whether fasting glucose levels might vary according to the percentage legume contribution per dish and the conclusions remained the same (data not shown).

Legumes are an important part of the prudent, Mediterranean, AHEI and Indo-Mediterranean diets ${ }^{(53-55,66)}$ which have shown benefits on cardiovascular risk factors and outcomes. Legumes' proposed benefits on diabetes risk may be mediated through multiple pathways, including the insoluble fibre and bioactive phytochemicals in the seeds' skin ${ }^{(67)}$, anti-inflammatory effects ${ }^{(68,69)}$, increase of gastric inhibitory polypeptide, and changes of the gut microbiota to increase insulin sensitivity ${ }^{(70-72)}$; the common processing of legumes also increases bioavailability of proteins and minerals by destroying antinutritional factors such as trypsin inhibitors, phytic acid and tannins ${ }^{(73,74)}$. A systematic review of randomized trials of non-oil seed pulses (i.e. legumes) on glycaemic control found that pulses alone significantly lowered fasting blood glucose (SMD $=-0 \cdot 81 ; 95 \% \mathrm{CI}-1 \cdot 36,-0 \cdot 27$ ) and insulin $(\mathrm{SMD}=-0.49 ; \quad 95 \% \text { CI }-0.93,0.04)^{(10)}$. However, the average sample size of these trials was small ( $n$ 23), the mean duration was short ( 6.7 weeks), only four of the eleven trials were considered to be of high quality (Heyland methodological quality score $\geq 8$ ) and the mean dosage in the intervention group was $50 \%$ higher than the highest quintile from our study population (mean dosage of pooled 11 trials $=152 \cdot 1 \mathrm{~g} / \mathrm{d}$ compared with $100 \cdot 7 \mathrm{~g} / \mathrm{d}$ in IMS $)^{(10)}$. In all but one trial ${ }^{(75)}$, the investigators designed extreme comparisons between entirely legume-based diets $v$. wheat-, bran- or vegetable-based diets, with zero legume intake in the control groups. Of forty-one total trials in the review, only one was conducted in India, which found benefits associated with the legume-enriched diet, but the diet was also fat-modified and supplemented with fruits, vegetables and moderate physical activity based on WHO recommendations ${ }^{(76)}$. A recent trial conducted after the review in India showed that adding legumes $50 \mathrm{~g} / \mathrm{d}$ for $5 \mathrm{~d}$ did not lower glycaemic and insulin response among overweight men and women above and beyond brown rice when compared with white rice diets ${ }^{(31)}$.

The present study is the first large-scale epidemiological study to evaluate legume consumption and biomarkers of glycaemic control, insulin resistance and diabetes in Indian diets representing rural and urban populations, and four different regions of the country. We used a validated 184-item semi-quantitative FFQ to capture the wide range of dishes consumed across four different regions of India and obtained fasting blood samples for biochemical marker measurement ${ }^{(77)}$. One limitation is that the FFQ may overestimate intakes of certain nutrients and not capture seasonal variation of fruit and vegetable intake; however, these should be sources of consistent measurement error across all members of the study population, therefore biasing our associations towards the null. There was limited power to detect an association with diabetes, given the low number of cases in this sample (3\%); these 
estimates tended towards positive associations and may reflect reverse causality due to diet-related changes from the diagnosis and management of diabetes. This may be a potential source of bias as evidenced from a sub-analysis excluding persons with diabetes, where we found a non-significant inverse trend $(P=0 \cdot 12)$ between legume consumption and fasting glucose $(\mathrm{Q} 1$ (reference); $\mathrm{Q} 2: \beta(\mathrm{mmol} / \mathrm{l})=-0 \cdot 13$; 95\% CI $-0.93,0 \cdot 66 ; \mathrm{Q} 3: \beta(\mathrm{mmol} / \mathrm{l})=-0 \cdot 21 ; 95 \% \mathrm{CI}-1 \cdot 11$, 0.69; Q4: $\beta(\mathrm{mmol} / \mathrm{l})=-0 \cdot 82 ; 95 \% \mathrm{CI}-1 \cdot 87,0 \cdot 22)$. Another consideration is the correlated data between urban-rural sibling pairs recruited for the study, with respect to risk factors and outcomes that are highly heritable ${ }^{(78)}$. We used a random-effects model to adjust for the within-pair sibling variation; moreover, outcomes such as fasting glucose, HOMA score and diabetes in our study population are more strongly associated with environmental factors, such as migration status $^{(34)}$, and its associated diets and physical activity patterns. And a stratified evaluation of the migration groups - rural, urban and rural-to-urban migrants, which broke the correlated data structure - yielded the same findings. The potential benefit of legumes may be masked by the counteracting harmful effects of other added ingredients (e.g. high sugar levels in legume sweets), the method of preparation (e.g. deep-fried legume snacks) and the varying contribution of legumes to legume dishes (e.g. 2-77 wt\%). Clinical trials are needed to evaluate the metabolic and biochemical effects of the various legume preparations in India (e.g. raw salads, steamed idlis, chutneys, fried dals and vegetables) to expand our understanding of the potential benefits and harms of these preparations, and to strengthen evidence-based guidelines on consuming more legumes for glycaemic control.

\section{Conclusions}

In a population with a relatively high-legume diet, we did not observe an association between legume consumption and markers of glycaemic control, insulin resistance or diabetes in a multicentre study of urban and rural diets from four geographic regions of India. It is worth noting that we observed inverse trends in the subgroups with highest levels of macronutrient intakes and lowest BMI. The nearly ubiquitous daily consumption of legume-based dishes contributed to high intakes in the reference group, which may have obscured our ability to detect an association and underlies the complexity and heterogeneity of Indian diets. Legume foods are an important component contributing to prudent, AHEI, Mediterranean and Indo-Mediterranean dietary patterns, and legume-derived edible oils should also be considered in the evaluation of legume intake.

\section{Acknowledgements}

Acknowledgements: The authors are grateful to the local investigators, fieldworkers and the participants of the IMS.
Financial support: Funding for the IMS was obtained from the Wellcome Trust (grant number GR070797MF) and P.K.D. was supported by a Wellcome Trust Strategic Award to the Public Health Foundation of India for the South Asia Network for Chronic Disease (grant number 084674/ Z/08/Z). Conflict of interest: None. Authorship: P.K.D. conducted the research, analysis and writing of the manuscript. L.B. and A.V.B. provided research, expertise and input towards development and validation of the FFQ. S.K. and S.A. provided insight and expertise on the analysis, tables and figures and manuscript. K.S.R., D.P. and S.E. were involved in the design, implementation and conduct of the study, as well as oversight and guidance throughout the process. All authors reviewed the final draft of the manuscript. The Indian Migration Study Group comprises the following. New Delhi: K. Srinath Reddy, Dorairaj Prabhakaran, Tulsi Patel, Lakshmy Ramakrishnan, Ruby Gupta, Tanica Lyngdoh; Lucknow: R.C. Ahuja, R.K. Saran; Nagpur: Prashant Joshi, N.M. Thakre; Hyderabad: K.V.R. Sarma, S. Mohan Das, R.K Jain, S.S. Potnis; Bangalore: Anura V. Kurpad, Mario Vaz, A.V. Barathi, Murali Mohan; Pune: Chittaranjan Yajnik; Bristol: George Davey Smith, Yoav Ben Shlomo; London School of Hygiene \& Tropical Medicine: Shah Ebrahim, Sanjay Kinra.

\section{Supplementary material}

To view supplementary material for this article, please visit http://dx.doi.org/10.1017/S1368980016001233

\section{References}

1. Cho NH, Whiting D, Guarigata L et al. (2013) IDF Diabetes Atlas, 6th ed. Brussels: International Diabetes Federation.

2. World Health Organization (2014) Global Health Estimates: Deaths by Cause, Age, Sex and Country, 2000-2012. Geneva: WHO.

3. Anjana RM, Pradeepa R, Deepa M et al. (2011) Prevalence of diabetes and prediabetes (impaired fasting glucose and/ or impaired glucose tolerance) in urban and rural India: phase I results of the Indian Council of Medical ResearchINdia DIABetes (ICMR-INDIAB) study. Diabetologia 54, 3022-3027.

4. Institute for Health and Metrics Evaluation (2013) IHME: Global Burden of Disease Study 2010. India Global Burden of Disease Study 2010 (GBD 2010): 1990-2010. Seattle, WA: IHME.

5. Naylor C, Parikh R, Negi S et al. (2015) Chronic Conditions in India: Evidence-Based Solutions for a Growing Health Crisis. New Delhi: Public Health Foundation of India.

6. Misra A, Singhal N, Sivakumar B et al. (2011) Nutrition transition in India: secular trends in dietary intake and their relationship to diet-related non-communicable diseases. J Diabetes 3, 278-292.

7. Harborne JB (editor) (1994) Phytochemical Dictionary of the Leguminosae. London: Chapman \& Hall.

8. Mann JI, De Leeuw I, Hermansen K et al. (2004) Evidence-based nutritional approaches to the treatment and prevention of diabetes mellitus. Nutr Metab Cardiovasc Dis 14, 373-394. 
9. Canadian Diabetes Association (2008) Canadian Diabetes Association 2008 clinical practice guidelines for the prevention and management of diabetes in Canada. Can J Diabetes 32, Suppl. 1, S1-S201.

10. Bantle JP, Wylie-Rosett J, Albright AL et al. (2008) Nutrition recommendations and interventions for diabetes: a position statement of the American Diabetes Association. Diabetes Care 31, Suppl. 1, S61-S78.

11. Tiwari RR, Deb PK, Debbarma A et al. (2008) Risk factor analysis in self-reported diabetes in a rural Kerala population. Int J Diabetes Dev Ctries 28, 91-94.

12. Vijayakumar G, Arun R \& Kutty VR (2009) High prevalence of type 2 diabetes mellitus and other metabolic disorders in rural Central Kerala. J Assoc Physicians India 57, 563-567.

13. Mohan V, Deepa M, Deepa R et al. (2006) Secular trends in the prevalence of diabetes and impaired glucose tolerance in urban South India - the Chennai Urban Rural Epidemiology Study (CURES-17). Diabetologia 49, 1175-1178.

14. Misra A, Pandey RM, Devi JR et al. (2001) High prevalence of diabetes, obesity and dyslipidaemia in urban slum population in northern India. Int J Obes Relat Metab Disord 25, 1722-1729.

15. Ramachandran A, Snehalatha C, Latha E et al. (1997) Rising prevalence of NIDDM in an urban population in India. Diabetologia 40, 232-237.

16. Ramachandran A, Snehalatha C \& Vijay V (2004) Low risk threshold for acquired diabetogenic factors in Asian Indians. Diabetes Res Clin Pract 65, 189-195.

17. Sievenpiper JL, Kendall CW, Esfahani A et al. (2009) Effect of non-oil-seed pulses on glycaemic control: a systematic review and meta-analysis of randomised controlled experimental trials in people with and without diabetes. Diabetologia 52, 1479-1495.

18. O'Keefe JH, Gheewala NM \& O'Keefe JO (2012) Dietary strategies for improving post-prandial glucose, lipids, inflammation, and cardiovascular health. J Am Coll Cardiol 51, 249-255.

19. Higgins JA (2012) Whole grains, legumes, and the subsequent meal effect: implications for blood glucose control and the role of fermentation. J Nutr Metab 2012, 829238.

20. Jenkins DJ, Kendall CW, Augustin LS et al. (2012) Effect of legumes as part of a low glycemic index diet on glycemic control and cardiovascular risk factors in type 2 diabetes mellitus: a randomized controlled trial. Arch Intern Med 172, 1653-1660.

21. Saraf-Bank S, Esmaillzadeh A, Faghihimani E et al. (2016) Effects of legume-enriched diet on cardiometabolic risk factors among individuals at risk for diabetes: a crossover study. J Am Coll Nutr 35, 31-40.

22. Feskens EJ, Bowles CH \& Kromhout D (1991) Carbohydrate intake and body mass index in relation to the risk of glucose intolerance in an elderly population. Am J Clin Nutr 54, 136-140.

23. Feskens EJ, Virtanen SM, Rasanen L et al. (1995) Dietary factors determining diabetes and impaired glucose tolerance. A 20-year follow-up of the Finnish and Dutch cohorts of the Seven Countries Study. Diabetes Care 18, 1104-1112.

24. Villegas R, Gao YT, Yang G et al. (2008) Legume and soy food intake and the incidence of type 2 diabetes in the Shanghai Women's Health Study. Am J Clin Nutr 87, 162-167.

25. Nanri A, Mizoue T, Takahashi Y et al. (2010) Soy product and isoflavone intakes are associated with a lower risk of type 2 diabetes in overweight Japanese women. J Nutr 140, 580-586.

26. Mueller NT, Odegaard AO, Gross MD et al. (2012) Soy intake and risk of type 2 diabetes mellitus in Chinese Singaporeans: soy intake and risk of type 2 diabetes. Eur J Nutr 51, 1033-1040.
27. Meyer KA, Kushi LH, Jacobs DR Jr et al. (2000) Carbohydrates, dietary fiber, and incident type 2 diabetes in older women. Am J Clin Nutr 71, 921-930.

28. Heidemann C, Hoffmann K, Spranger J et al. (2005) A dietary pattern protective against type 2 diabetes in the European Prospective Investigation into Cancer and Nutrition (EPIC)-Potsdam Study cohort. Diabetologia 48, $1126-1134$.

29. Morimoto Y, Steinbrecher A, Kolonel LN et al. (2011) Soy consumption is not protective against diabetes in Hawaii: the Multiethnic Cohort. Eur J Clin Nutr 65, 279-282.

30. Agrawal S \& Ebrahim S (2013) Association between legume intake and self-reported diabetes among adult men and women in India. BMC Public Health 13, 706.

31. Mohan V, Spiegelman D, Sudha V et al. (2014) Effect of brown rice, white rice, and brown rice with legumes on blood glucose and insulin responses in overweight Asian Indians: a randomized controlled trial. Diabetes Technol Ther 16, 317-325.

32. Singh PN, Arthur KN, Orlich MJ et al. (2014) Global epidemiology of obesity, vegetarian dietary patterns, and noncommunicable disease in Asian Indians. Am J Clin Nutr 100, Suppl. 1, 359S-364S.

33. Ley SH, Hamdy O, Mohan V et al. (2014) Prevention and management of type 2 diabetes: dietary components and nutritional strategies. Lancet 383, 1999-2007.

34. Ebrahim S, Kinra S, Bowen L et al. (2010) The effect of rural-to-urban migration on obesity and diabetes in India: a cross-sectional study. PLoS Med 7, e1000268.

35. Bowen L, Bharathi AV, Kinra S et al. (2012) Development and evaluation of a semi-quantitative food frequency questionnaire for use in urban and rural India. Asia Pac J Clin Nutr 21, 355-360.

36. Gopalan C (1971) Nutritive Value of Indian Foods. Hyderabad: National Institute of Nutrition.

37. US Department of Agriculture Nutrient (2006) Data Laboratory. http://www.ars.usda.gov/nutrientdata

38. Welch AA, Unwin ID, Buss DH et al. (1995) McCance and Widdowson's The Composition of Foods. Cambridge: Royal Society of Chemistry.

39. Parr CL, Veierod MB, Laake P et al. (2006) Test-retest reproducibility of a food frequency questionnaire (FFQ) and estimated effects on disease risk in the Norwegian Women and Cancer Study (NOWAC). Nutr J 5, 4.

40. Marchioni DM, Voci SM, Lima FE et al. (2007) Reproducibility of a food frequency questionnaire for adolescents. Cad Saude Publica 23, 2187-2196.

41. Indian Institute for Population Sciences (2007) The Third National Family Health Survey, 2005-06 (NFHS-3). Mumbai: IIPS.

42. Subramanian SV, Nandy S, Irving M et al. (2006) The mortality divide in India: the differential contributions of gender, caste, and standard of living across the life course. Am J Public Health 96, 818-825.

43. Subramanian SV, Davey Smith G \& Subramanyam M (2006) Indigenous health and socioeconomic status in India. PLOS Med 3, e421.

44. Bharathi AV, Kuriyan R, Kurpad AV et al. (2010) Assessment of physical activity using accelerometry, an activity diary, the heart rate method and the Indian migration study questionnaire in south Indian adults. Public Health Nutr 13, $47-53$.

45. Sullivan R, Kinra S, Ekelund U et al. (2011) Sociodemographic patterning of physical activity across migrant groups in India: results from the Indian Migration Study. PLoS One 6, e24898.

46. Alberti KGG \& Zimmet PZ; WHO Consultation (2002) Definition, Diagnosis, and Classification of Diabetes Mellitus and its Complications. Report of a WHO 
Consultation. Part I: Diagnosis and Classification of Diabetes Mellitus. Geneva: WHO.

47. Trinder P (1969) Determination of blood glucose using 4aminophenazone as oxygen acceptor. J Clin Pathol 22, 246.

48. Levy JC, Matthews DR \& Hermans MP (1998) Correct homeostasis model assessment (HOMA) evaluation uses the computer program. Diabetes Care 21, 2191-2192.

49. Duseja A, Thumburu KK, Das A et al. (2007) Insulin tolerance test is comparable to homeostasis model assessment for insulin resistance in patients with non-alcoholic fatty liver disease. Indian J Gastroenterol 26, 170-173.

50. Kirkwood BR \& Sterne JAC (2003) Analysis of clustered data. In Essential Medical Statistics, 2nd ed., pp. 355-370. Oxford: Blackwell Science Ltd.

51. Singhal P, Kaushik G \& Mathur P (2014) Antidiabetic potential of commonly consumed legumes: a review. Crit Rev Food Sci Nutr 54, 655-672.

52. Salas-Salvado J, Martinez-Gonzalez MA, Bullo M et al. (2011) The role of diet in the prevention of type 2 diabetes. Nutr Metab Cardiovasc Dis 21, Suppl. 2, B32-B48.

53. Fung TT, Schulze M, Manson JE et al. (2004) Dietary patterns, meat intake, and the risk of type 2 diabetes in women. Arch Intern Med 164, 2235-2240.

54. Chiuve SE, Fung TT, Rimm EB et al. (2012) Alternative dietary indices both strongly predict risk of chronic disease. J Nutr 142, 1009-1018.

55. Trichopoulos D \& Lagiou P (2004) Mediterranean diet and cardiovascular epidemiology. Eur J Epidemiol 19, 7-8.

56. Martinez-Gonzalez MA, de la Fuente-Arrillaga C, NunezCordoba JM et al. (2008) Adherence to Mediterranean diet and risk of developing diabetes: prospective cohort study. BMJ 336, 1348-1351.

57. InterAct Consortium, Romaguera D \& Guevara M (2011) Mediterranean diet and type 2 diabetes risk in the European Prospective Investigation into Cancer and Nutrition (EPIC) study: the InterAct project. Diabetes Care 34, 1913-1918.

58. Odegaard AO, Koh WP, Butler LM et al. (2011) Dietary patterns and incident type 2 diabetes in Chinese men and women: the Singapore Chinese Health Study. Diabetes Care 34, 880-885.

59. Riserus U, Willett WC \& Hu FB (2009) Dietary fats and prevention of type 2 diabetes. Prog Lipid Res 48, 44-51.

60. Salmeron J, Hu FB, Manson JE et al. (2001) Dietary fat intake and risk of type 2 diabetes in women. Am J Clin Nutr $\mathbf{7 3}$, 1019-1026.

61. Meyer KA, Kushi LH, Jacobs DR Jr et al. (2001) Dietary fat and incidence of type 2 diabetes in older Iowa women. Diabetes Care 24, 1528-1535.

62. van Dam RM, Willett WC, Rimm EB et al. (2002) Dietary fat and meat intake in relation to risk of type 2 diabetes in men. Diabetes Care 25, 417-424.

63. Harding AH, Day NE, Khaw KT et al. (2004) Dietary fat and the risk of clinical type 2 diabetes: the European Prospective Investigation of Cancer-Norfolk study. Am J Epidemiol 159, $73-82$.
64. Hu FB, van Dam RM \& Liu S (2001) Diet and risk of type II diabetes: the role of types of fat and carbohydrate. Diabetologia 44, 805-817.

65. Hodge AM, English DR, O'Dea K et al. (2007) Plasma phospholipid and dietary fatty acids as predictors of type 2 diabetes: interpreting the role of linoleic acid. Am J Clin Nutr 86, 189-197.

66. Singh RB, Dubnov G, Niaz MA et al. (2002) Effect of an Indo-Mediterranean diet on progression of coronary artery disease in high risk patients (Indo-Mediterranean Diet Heart Study): a randomised single-blind trial. Lancet 360, 1455-1461.

67. Marquart L, Slavin JL \& Fulcher RG (2002) Whole-Grain Foods in Health and Disease. St. Paul, MN: American Association of Cereal Chemists.

68. Saraf-Bank S, Esmaillzadeh A, Faghihimani E et al. (2015) Effect of non-soy legume consumption on inflammation and serum adiponectin levels among first-degree relatives of patients with diabetes: a randomized, crossover study. Nutrition 31, 459-465.

69. Salehi-Abargouei A, Saraf-Bank S, Bellissimo N et al. (2015) Effects of non-soy legume consumption on C-reactive protein: a systematic review and meta-analysis. Nutrition 31, 631-639.

70. Weickert MO, Mohlig M, Koebnick C et al. (2005) Impact of cereal fibre on glucose-regulating factors. Diabetologia 48, 2343-2353.

71. Ma Y, Griffith JA, Chasan-Taber L et al. (2006) Association between dietary fiber and serum C-reactive protein. Am J Clin Nutr 83, 760-766.

72. Weickert MO \& Pfeiffer AF (2008) Metabolic effects of dietary fiber consumption and prevention of diabetes. J Nutr 138, 439-442.

73. Tharanthan RN \& Mahedevamma S (2003) Grain legumes a boon to human nutrition. Trends Food Sci Technology 14, 507-518.

74. Hefnawy TH (2011) Effect of processing methods on nutritional composition and anti-nutritional factors in lentils (Lens culinaris). Ann Agric Sci 56, 5.

75. Jang Y, Lee JH, Kim OY et al. (2001) Consumption of whole grain and legume powder reduces insulin demand, lipid peroxidation, and plasma homocysteine concentrations in patients with coronary artery disease: randomized controlled clinical trial. Arterioscler Thromb Vasc Biol 21, 2065-2071.

76. Singh RB, Rastogi V, Rastogi SS et al. (1996) Effect of diet and moderate exercise on central obesity and associated disturbances, myocardial infarction and mortality in patients with and without coronary artery disease. J Am Coll Nutr 15, 592-601.

77. Bowen L, Ebrahim S, De Stavola B et al. (2011) Dietary intake and rural-urban migration in India: a crosssectional study. PLoS One 6, e14822.

78. Lyngdoh T, Kinra S, Shlomo YB et al. (2006) Sib-recruitment for studying migration and its impact on obesity and diabetes. Emerg Themes Epidemiol 3, 2. 